\title{
BMJ Open Atrial fibrillation in Indigenous and non-Indigenous Australians: a cross-sectional study
}

Christopher X Wong, ${ }^{1}$ Anthony G Brooks, ${ }^{1}$ Yi-Han Cheng, ${ }^{1}$ Dennis H Lau, ${ }^{1}$ Geetanjali Rangnekar, ${ }^{1}$ Kurt C Roberts-Thomson, ${ }^{1}$ Jonathan M Kalman, ${ }^{2,3}$ Alex Brown, ${ }^{4}$ Prashanthan Sanders ${ }^{1}$

To cite: Wong $C X$, Brooks AG, Cheng Y-H, et al. Atrial fibrillation in Indigenous and nonIndigenous Australians: a cross-sectional study. BMJ Open 2014;4:e006242. doi:10.1136/bmjopen-2014006242

- Prepublication history for this paper is available online. To view these files please visit the journal online (http://dx.doi.org/10.1136/ bmjopen-2014-006242).

Received 1 August 2014 Revised 30 September 2014 Accepted 3 October 2014

CrossMark

\begin{abstract}
${ }^{1}$ Centre for Heart Rhythm Disorders (CHRD), South Australian Health and Medical Research Institute (SAHMRI), University of Adelaide and Royal Adelaide Hospital, Adelaide, Australia 2Department of Cardiology, Royal Melbourne Hospital, Melbourne, Australia

${ }^{3}$ Department of Medicine, University of Melbourne, Melbourne, Australia ${ }^{4}$ Aborginal Health Research, South Australian Health and Medical Research Institute (SAHMRI) and School of Population Health, University of South Australia, Adelaide, Australia
\end{abstract}

Correspondence to Dr Christopher X Wong; c.wong@adelaide.edu.au

\section{ABSTRACT}

Objective: To examine the prevalence of atrial fibrillation (AF) and cardiac structural characteristics in Indigenous and non-Indigenous Australians.

Design: Retrospective cross-sectional study linking clinical, echocardiography and administrative databases over a 10-year period.

Setting: A tertiary, university teaching hospital in Adelaide, Australia.

Participants: Indigenous and non-Indigenous Australians.

Main outcome measures: AF prevalence and echocardiographic characteristics.

Results: Indigenous Australians with AF were significantly younger compared to non-Indigenous Australians ( $55 \pm 13$ vs $75 \pm 13$ years, $p<0.001$ ). As a result, racial differences in AF prevalence and left atrial diameter varied according to age. In those under 60 years of age, Indigenous Australians had a significantly greater AF prevalence (2.57 vs $1.73 \%$, $p<0.001)$ and left atrial diameters $(39 \pm 7$ vs $37 \pm 7 \mathrm{~mm}$, $p<0.001)$ compared to non-Indigenous Australians. In those aged 60 years and above, however, nonIndigenous Australians had significantly greater AF prevalence ( 9.26 vs $4.61 \%, p<0.001)$ and left atrial diameters ( $39 \pm 7$ vs $37 \pm 7 \mathrm{~mm}, p<0.001)$. Left ventricular ejection fractions were less in Indigenous Australians under 60 years of age $(49 \pm 14$ vs $55 \pm 11 \%$, $p<0.001)$ and not statistically different in those aged 60 years and above $(47 \pm 11$ vs $52 \pm 13, p=0.074)$ compared to non-Indigenous Australians. Despite their younger age, Indigenous Australians with AF had similar or greater rates of cardiovascular comorbidities than non-Indigenous Australians with AF.

Conclusions: Young Indigenous Australians have a significantly greater prevalence of $\mathrm{AF}$ than their nonIndigenous counterparts. In contrast, older nonIndigenous Australians have a greater prevalence of AF compared to their Indigenous counterparts. These observations may be mediated by age-based differences in comorbid cardiovascular conditions, left atrial diameter and left ventricular ejection fraction. Our findings suggest that $A F$ is likely to be contributing to the greater burden of morbidity and mortality experienced by young Indigenous Australians. Further study is required to elucidate whether strategies to

\section{Strengths and limitations of this study}

- This study describes the prevalence of atrial fibrillation (AF) in Indigenous Australians which has not been previously characterised.

- We found that young Indigenous Australians have a significantly greater prevalence of AF compared to their non-Indigenous counterparts. In contrast, $\mathrm{AF}$ was more prevalent in elderly non-Indigenous Australians compared to Indigenous Australians.

- Age-based differences in comorbid cardiovascular conditions, left atrial dilatation and left ventricular dysfunction may in-part explain our observations.

- Limitations of this study include the potential for asymptomatic AF to not be detected, potential incomplete identification of Indigenous Australian race and the mainly hospital and urban-based participants.

prevent and better manage AF in Indigenous Australians may reduce this burden.

\section{INTRODUCTION}

Atrial fibrillation (AF) is the most common clinical arrhythmia and has a rising prevalence. ${ }^{1-7}$ As a result, recent data suggest that the burden of AF may already exceed that of other common cardiovascular conditions. ${ }^{6}$

Despite the frequency of cardiovascular disease in Indigenous Australians, AF is a condition that remains to be characterised in this population. Given the emerging evidence from other countries suggesting that $\mathrm{AF}$ may vary according to race, ${ }^{2} 8-12$ we sought to characterise the prevalence of $\mathrm{AF}$ in Indigenous and non-Indigenous Australians. Given the strong relationship between cardiac structure and AF, in particular left atrial diameter, we also examined for racial differences in echocardiographic characteristics. 


\section{METHODS}

\section{Study population}

The Royal Adelaide Hospital is a large tertiary referral centre and teaching hospital of the Universities of Adelaide and South Australia. We identified all Indigenous and non-Indigenous individuals admitted over a 10-year period from 2000 through 2009 inclusive from the coding database.

\section{Data collection}

The International Classification of Diseases, 10th Rev, Australian Modification (ICD-10-AM) was used for coding hospital diagnoses. AF was defined for patients with ICD-10-AM diagnosis code I48 that include AF and atrial flutter. Hypertension was defined for patients with ICD-10-AM diagnosis codes I10-I15. Ischaemic heart disease was defined for patients with ICD-10-AM diagnosis codes I20-I25. Heart failure was defined for patients with ICD-10-AM diagnosis code I50. Conditions were deemed to be present if they were coded as being either a principal or secondary diagnosis during any hospitalisation. In addition, it was noted whether these conditions were pre-existing at first clinical contact, or whether they were new diagnoses performed during study period at subsequent hospitalisations.

\section{Echocardiographic study}

A subset of individuals underwent resting transthoracic two-dimensional guided M-mode Doppler echocardiograms undertaken with standard techniques in the left lateral decubitus position. Patients with AF were excluded from this analysis. Standard M-mode left atrial linear dimensions were obtained from the parasternal long-axis view in end systole. ${ }^{13}$ Measurements of left ventricular enddiastolic diameter, left ventricular end-systolic diameter and left ventricular ejection fraction were additionally determined in accordance with the American Society of Echocardiography guidelines. ${ }^{13}$ Left ventricular ejection fraction was calculated using Biplane Simpson's rule.

\section{Statistical analysis}

Continuous variables are reported as mean $\pm \mathrm{SD}$ as appropriate. Study sample characteristics were compared using an independent samples $t$ test or $\chi^{2}$ test as appropriate. Binary logistic regression analyses were employed to determine associations with prevalent AF. Binary linear regression analyses were employed to determine associations with echocardiographic characteristics. Statistical tests were performed using SAS V.9.2 (SAS Institute Inc, Cary, North Carolina, USA) and $\mathrm{p}<0.05$ was considered significant.

\section{RESULTS \\ Patient characteristics}

A total of 629024 hospitalisations for 204668 individuals were identified (table 1). Of these, $22821(3.6 \%)$ and 606203 (96.4\%) hospitalisations were for Indigenous and non-Indigenous Australians, respectively. Compared to non-Indigenous Australians, Indigenous Australians were more likely to be younger and woman. While pre-existing hypertension, new hypertension, new ischaemic heart disease and new congestive heart failure were more prevalent in non-Indigenous Australians, pre-existing ischaemic heart disease was more prevalent in Indigenous Australians. There were no significant racial differences in the prevalence of pre-existing congestive heart failure.

\section{Race and AF}

A total of 14373 individuals had a diagnosis of AF. Overall, Indigenous Australian AF patients were younger than non-Indigenous Australian AF patients $(55 \pm 13$ vs 75 $\pm 13, \mathrm{p}<0.0001)$. As a result, the prevalence of $\mathrm{AF}$ in Indigenous and non-Indigenous Australians differed according to age. In those under 60 years of age, the prevalence of $\mathrm{AF}$ was greater in Indigenous Australians (2.57 vs $1.73 \%, \mathrm{p}<0.0001$; see figure 1 ). In contrast, in those aged 60 years and above, the prevalence of $\mathrm{AF}$ was greater in non-Indigenous Australians (9.26 vs 4.61\%, $\mathrm{p}<0.0001)$.

Table 1 Patient characteristics

\begin{tabular}{|c|c|c|c|c|c|c|}
\hline & $\begin{array}{l}\text { All } \\
\text { Indigenous } \\
\text { Australians } \\
(n=5892)\end{array}$ & $\begin{array}{l}\text { All non- } \\
\text { Indigenous } \\
\text { Australians } \\
(n=198776)\end{array}$ & p Value & $\begin{array}{l}\text { Indigenous } \\
\text { Australians } \\
\text { with AF } \\
(n=221)\end{array}$ & $\begin{array}{l}\text { Non-Indigenous } \\
\text { Australians } \\
\text { with AF } \\
(n=14152)\end{array}$ & p Value \\
\hline Age, year (SD) & $42.2(16.2)$ & $54.0(20.9)$ & $<0.001$ & $55.4(13.2)$ & $74.5(13.1)$ & $<0.001$ \\
\hline Male, \% (n) & 51.7 (3049) & $53.8(106992)$ & 0.002 & $52.5(116)$ & $54.1(7662)$ & 0.63 \\
\hline Pre-existing hypertension, \% (n) & $15.0(886)$ & $47.9(24478)$ & $<0.001$ & $32.6(72)$ & 32.1 (4539) & 0.87 \\
\hline New hypertension, \% (n) & $4.3(252)$ & $19.8(10103)$ & $<0.001$ & $16.3(36)$ & $16.5(2329)$ & 0.95 \\
\hline $\begin{array}{l}\text { Pre-existing ischaemic heart disease, } \\
\%(n)\end{array}$ & $13.3(783)$ & $9.6(19071)$ & $<0.001$ & $36.2(80)$ & $26.3(3715)$ & $<0.001$ \\
\hline New ischaemic heart disease, \% (n) & $2.6(153)$ & $3.1(6096)$ & 0.04 & $13.1(29)$ & $12.6(1777)$ & 0.80 \\
\hline Pre-existing congestive heart failure, \% (n) & $3.3(193)$ & $3.3(6504)$ & 0.99 & $17.2(38)$ & 17.7 (2504) & 0.85 \\
\hline New congestive heart failure, $\%(n)$ & $1.7(101)$ & $2.5(4936)$ & $<0.001$ & $16.7(37)$ & $15.2(2149)$ & 0.52 \\
\hline
\end{tabular}




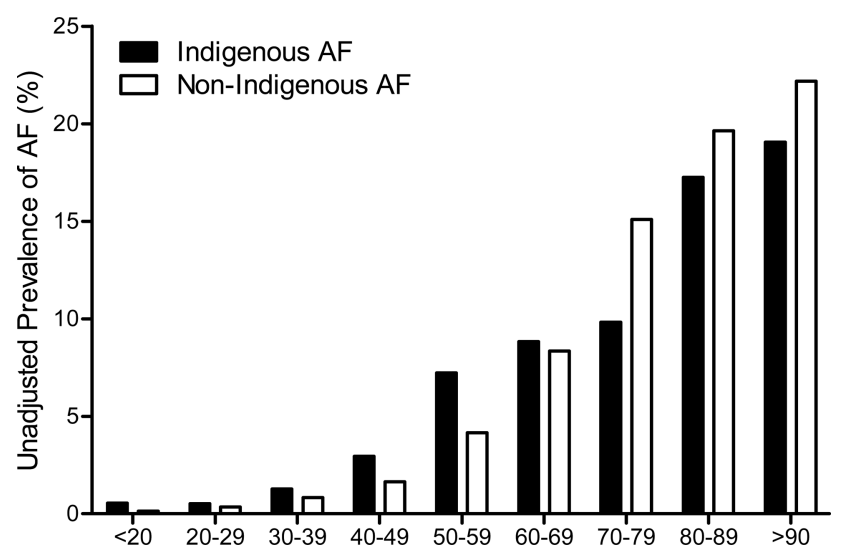

Figure 1 Graph showing the race-specific prevalence of atrial fibrillation in Indigenous and non-Indigenous Australians according to age group.

Despite their younger age, Indigenous Australian AF patients had a similar or greater prevalence of cardiovascular comorbidities than their non-Indigenous counterparts (table 1). As a result, controlling for these comorbidities in multivariable analyses attenuated the relationship between Indigenous Australian status and prevalent AF (table 2).

\section{Echocardiography characteristics}

A total of 4477 echocardiograms were analysed. The mean left atrial diameter was $38 \pm 7 \mathrm{~mm}$ and mean left ventricular ejection fraction $53 \pm 12 \%$. Echocardiographic characteristics also exhibited racial variation according to age. In those under 60 years of age, Indigenous Australians had a greater mean left atrial diameter (39 \pm 7 vs $37 \pm 7 \mathrm{~mm}, \mathrm{p}<0.001)$. In those aged 60 years and above, non-Indigenous Australians had a greater mean left atrial diameter $(39 \pm 7$ vs $37 \pm 7 \mathrm{~mm}, \mathrm{p}<0.001)$. Left ventricular ejection fractions were lesser in Indigenous Australians under 60 years of age $(49 \pm 14$ vs $55 \pm 11 \%$, $\mathrm{p}<0.001)$ though not in those aged 60 years and above $(47 \pm 11$ vs $52 \pm 13, \mathrm{p}=0.074)$. In multivariable-adjusted regression models, Indigenous Australian status remained significantly associated with greater left atrial diameter and lower left ventricular ejection fraction (tables 3 and 4).

\section{DISCUSSION}

\section{Major findings}

This report provides the first comparative assessment of $\mathrm{AF}$ in Indigenous and non-Indigenous Australians. We found that AF was more prevalent among Indigenous Australians under 60 years of age and more prevalent in non-Indigenous Australians aged 60 years and above. Indigenous Australians under 60 years of age, but not those aged 60 years and above, had significantly greater left atrial diameters and rates of left ventricular systolic dysfunction than non-Indigenous counterparts after multivariable adjustment. These differences in cardiac structure and function may in-part explain the excess prevalence of AF seen in young Indigenous Australians that would contribute to the disparity in lifeexpectancies between Indigenous and non-Indigenous Australians.

\section{Evidence for racial variation in the prevalence of AF}

A number of previous studies have reported that Caucasian race is associated with a greater prevalence of $\mathrm{AF}$ and that African American race is associated with a lower prevalence of AF. ${ }^{2-12}$ Since then, further differences in the prevalence of AF have been variably noted in Chinese, Japanese, Korean, African and Latino populations. $^{12}{ }^{14-20}$ Despite the above studies, however, there continues to be a paucity of epidemiological data on AF from many parts of the world, including Australasia.

In the present study, we thus sought to characterise AF in hospitalised Indigenous Australians. Compared to their non-Indigenous counterparts, we found a greater prevalence of AF in young Indigenous Australians, and in contrast, a lesser prevalence of $\mathrm{AF}$ in older Indigenous Australians.

\section{Possible mechanisms underlying racial differences in AF prevalence}

Despite the expanding literature describing racial differences in $\mathrm{AF}$ prevalence, the mechanisms underlying these observations remain unclear. There is a growing body of evidence suggesting that there exists a genetic predisposition to $\mathrm{AF}^{21}$ Since familial AF was first reported in 1942, recent studies have shown an increased risk of AF associated with family history, various mutations and genetic loci. ${ }^{22}$ One study

Table 2 Multivariable-adjusted associations with prevalent atrial fibrillation

\begin{tabular}{lcccr}
\hline & Univariate OR $(\mathbf{C l})$ & $\mathbf{p ~ V a l u e}$ & Multivariate OR $(\mathbf{C l})$ & $\mathbf{p ~ V a l u e}$ \\
\hline Indigenous Australian & $1.471(1.233$ to 1.755$)$ & $<0.001$ & $1.183(0.977$ to 1.432$)$ & 0.085 \\
Age & $1.086(1.082$ to 1.091$)$ & $<0.001$ & $1.069(1.064$ to 1.074$)$ & $<0.001$ \\
Male & $1.992(1.817$ to 2.185$)$ & $<0.001$ & $1.798(1.633$ to 1.979$)$ & $<0.001$ \\
Hypertension & $6.138(5.603$ to 6.723$)$ & $<0.001$ & $2.109(1.892$ to 2.352$)$ & $<0.001$ \\
Ischaemic heart disease & $6.341(5.761$ to 6.979$)$ & $<0.001$ & $1.556(1.383$ to 1.750$)$ & $<0.001$ \\
Congestive heart failure & $21.562(19.146$ to 24.283$)$ & $<0.001$ & $8.812(7.72$ to 10.059$)$ & $<0.001$ \\
\hline
\end{tabular}


Table 3 Multivariable-adjusted associations with left atrial diameter

\begin{tabular}{|c|c|c|c|c|}
\hline & Univariate regressions $(\mathrm{Cl})$ & p Value & Multivariate regressions $(\mathrm{Cl})$ & p Value \\
\hline Indigenous Australian & $0.255(0.143$ to 0.367$)$ & $<0.001$ & 0.261 (0.096 to 0.426$)$ & 0.002 \\
\hline Age & $0.016(0.013$ to 0.018$)$ & $<0.001$ & $0.012(0.008$ to 0.016$)$ & $<0.001$ \\
\hline Male & $0.299(0.234$ to 0.365$)$ & $<0.001$ & 0.344 (0.249 to 0.439$)$ & $<0.001$ \\
\hline Hypertension & 0.249 (0.169 to 0.329$)$ & $<0.001$ & 0.135 (0.011 to 0.259$)$ & $<0.001$ \\
\hline Ischaemic heart disease & 0.301 (0.224 to 0.379$)$ & $<0.001$ & $0.043(-0.071$ to 0.156$)$ & 0.46 \\
\hline Congestive heart failure & 0.653 (0.530 to 0.775$)$ & $<0.001$ & 0.417 (0.232 to 0.602$)$ & $<0.001$ \\
\hline LV ejection fraction & $-0.022(-0.026$ to -0.018$)$ & $<0.001$ & $-0.012(-0.017$ to -0.008$)$ & $<0.001$ \\
\hline
\end{tabular}

described how European ancestry was a risk factor for developing AF, however, we are not aware of any comparable reports including Indigenous Australians. ${ }^{23}$ It has also been hypothesised that genes governing atrial dimensions may be responsible. Left atrial diameter is a well-established risk factor for $\mathrm{AF}^{9}$ Two previous studies have noted smaller left atria in African Americans compared to Caucasians, which they hypothesised might contribute to their lower burden of AF. ${ }^{1224}$ Our finding that Indigenous Australians have larger left atria may thus in-part explain the excess burden of AF seen in younger Indigenous Australians observed in the present study. Similarly, left ventricular systolic dysfunction is a powerful risk factor for $\mathrm{AF}$ and our data confirm the previously described excess burden of ventricular dysfunction in Indigenous Australians. ${ }^{25}$

Varying risk factor profiles have also been previously speculated to be in-part responsible for racial differences in AF. Indigenous Australians have an excess burden of cardiovascular disease and a 11-year lower life expectancy compared to other Australians, reflecting entrenched social, economic and educational disadvantage. $^{26}{ }^{27}$ In recent data from the Heart of the Heart Study, comprehensive heart failure and risk factors data in Indigenous Australians was reported. ${ }^{25}$ In six Indigenous Australian communities in Central Australia, the burden of heart failure and risk factors was extremely high. Consistent with these findings, in our hospitalised and comparatively urban population of Indigenous Australians with AF, we also noted similar or greater rates of cardiovascular comorbidities compared to non-Indigenous Australians, despite their younger age. However, varying risk factor profiles are not always consistent with racial differences in $\mathrm{AF}$ prevalence; in
African-American populations, for example, there is a paradoxically lower prevalence of $\mathrm{AF}$ in spite of their greater risk factor burden. ${ }^{28} 29$

It has also been hypothesised that under ascertainment of AF could explain some divergences, with a reported lower burden of AF in African-Americans potentially a result of poorer access to medical care. However, under ascertainment would be less likely in prior reports from integrated healthcare facilities and prospective studies where the ability to diagnose AF has been consistent across races. ${ }^{2}{ }^{12}$ Additionally, this would not readily explain the greater, and not lesser, burden of AF noted in younger Indigenous Australians observed in the present study.

Differences in mortality might in-part explain the greater AF prevalence seen in older non-Indigenous Australians. The disproportionately early morbidity and mortality faced by Indigenous Australians could in turn lead to a lower prevalence of AF in older age groups if only healthier individuals survived; simultaneously, access to better medical care in non-Indigenous Australians would improve survival despite concurrent comorbidities such as AF. Such a possible mortality difference may have resulted in the similar overall prevalence of AF observed after multivariable adjustment, despite the greater prevalence of $\mathrm{AF}$ in younger Indigenous Australians.

\section{Implications}

From a mechanistic perspective, our findings further support the notion that differences in cardiac structure and function may underlie racial variation in AF prevalence. On a clinical level, the excess burden of AF and other comorbidities observed in young Indigenous

Table 4 Multivariable-adjusted associations with left ventricular ejection fraction

\begin{tabular}{llccc}
\hline & Univariate & p Value & Multivariate & $\mathbf{p ~ V a l u e ~}$ \\
\hline Indigenous Australian & $-5.915(-8.908$ to -2.923$)$ & $<0.001$ & $-5.050(-7.621$ to -2.479$)$ \\
Age & $-0.101(-0.164$ to -0.038$)$ & 0.002 & $-0.049(-0.105$ to 0.008$)$ & $<0.001$ \\
Male & $-2.166(-3.940$ to -0.039$)$ & 0.017 & $-2.525(-4.015$ to -1.035$)$ & 0.09 \\
Hypertension & $-3.266(-5.436$ to -1.096$)$ & 0.003 & $-0.675(-2.626$ to 1.276$)$ & 0.001 \\
Ischaemic heart disease & $-5.575(-7.500$ to -3.651$)$ & $<0.001$ & $-3.324(-5.098$ to -1.550$)$ & $<0.001$ \\
Congestive heart failure & $-21.225(-23.735$ to -18.715$)$ & $<0.001$ & $-20.632(-23.120$ to -18.144$)$ & $<0.001$ \\
\hline
\end{tabular}


Australians is of concern. These data suggest that risk factor modification may mitigate the excess burden of morbidity and mortality due to $\mathrm{AF}$ in younger Indigenous Australians.

\section{Study limitations}

Our study has a number of limitations which limit the genereralisability of our results. First, asymptomatic AF may not have been detected. Second, there may be incomplete identification of Indigenous Australians in hospital records given race was self-reported and the racial make-up of any given individual can be complex; however, we demonstrated a difference in AF prevalence in spite of this. Third, a significant number of Indigenous Australians reside in rural regions, compared to the presently studied urban setting. Fourth, our cohort comprised hospitalised patients who, in contrast to the general population, have a greater prevalence of comorbidities and thus AF. As a result, our findings may not necessarily reflect that of the general population. Finally, there may be other potential confounders that were not measured, including differences in lifestyle factors and other predictors of $\mathrm{AF}$ such as diabetes, obesity and obstructive sleep apnoea. ${ }^{30}$

\section{CONCLUSION}

To the best of our knowledge, the present study provides the first assessment of AF in Indigenous Australians. Young, hospitalised Indigenous Australians have a significantly greater prevalence of $\mathrm{AF}$ than their non-Indigenous counterparts. These findings may be due in-part to more frequent comorbidities, larger left atrial dimensions and greater rates of left ventricular systolic dysfunction observed in young Indigenous Australians.

Acknowledgements Mr Thomas Sullivan B.Ma.Comp.Sci(Hons.) from the Discipline of Public Health, University of Adelaide, assisted in the statistical analysis.

Contributors CXW, AGB, and PS were involved in the study conception and design. CXW and AGB were involved in acquisition of data. CXW, AGB, Y-HC, DHL, GR, KCR-T, JMK, AB and PS were responsible for analysis and interpretation for data. CXW drafted the manuscript and all authors critically revised it for intellectual content.

Funding CXW is supported by a Rhodes Scholarship and a Postgraduate Scholarship from the National Health and Medical Research Council of Australia (NHMRC). DHL is supported by a Postdoctoral Fellowship from the NHMRC. AGB, KCR-T and PS are supported by the National Heart Foundation of Australia. JMK and PS are supported by Practitioner Fellowships from the NHMRC.

Competing interests KCR-T has served on the advisory board of St Jude Medical. PS has served on the advisory board of and has received lecture fees and research funding from Bard Electrophysiology, Biosense-Webster, Medtronic, St Jude Medical, Merck Sharp and Dohme and Sanofi-Aventis.

Patient consent Obtained.

Ethics approval The study protocol was approved by the Human Research Ethics Committee of the Royal Adelaide Hospital, Adelaide, Australia.

Provenance and peer review Not commissioned; externally peer reviewed.
Data sharing statement No additional data are available.

Open Access This is an Open Access article distributed in accordance with the Creative Commons Attribution Non Commercial (CC BY-NC 4.0) license, which permits others to distribute, remix, adapt, build upon this work noncommercially, and license their derivative works on different terms, provided the original work is properly cited and the use is non-commercial. See: http:// creativecommons.org/licenses/by-nc/4.0/

\section{REFERENCES}

1. Wong CX, Lau DH, Sanders P. Atrial fibrillation epidemic and hospitalizations: how to turn the rising tide? Circulation 2014;129:2361-3.

2. Go AS, Hylek EM, Phillips KA, et al. Prevalence of diagnosed atria fibrillation in adults: national implications for rhythm management and stroke prevention: the AnTicoagulation and Risk Factors in Atrial Fibrillation (ATRIA) Study. JAMA 2001;285:2370-5.

3. Miyasaka Y, Barnes ME, Gersh BJ, et al. Secular trends in incidence of atrial fibrillation in Olmsted County, Minnesota, 1980 to 2000, and implications on the projections for future prevalence. Circulation 2006;114:119-25

4. Stewart S, Murphy N, Walker A, et al. Cost of an emerging epidemic: an economic analysis of atrial fibrillation in the UK. Heart 2004:90:286-92.

5. Wattigney WA, Mensah GA, Croft JB. Increasing trends in hospitalization for atrial fibrillation in the United States, 1985 through 1999: implications for primary prevention. Circulation 2003;108:711-16.

6. Wong CX, Brooks AG, Leong DP, et al. The increasing burden of atrial fibrillation compared to heart failure and myocardial infarction a 15-year study of all hospitalizations in Australia. Arch Intern Med 2012;172:739-41.

7. Wong CX, Brooks AG, Lau DH, et al. Factors associated with the epidemic of hospitalizations due to atrial fibrillation. Am J Cardiol 2012;110:1496-9.

8. Alonso A, Agarwal SK, Soliman EZ, et al. Incidence of atrial fibrillation in whites and African-Americans: the Atherosclerosis Risk in Communities (ARIC) study. Am Heart J 2009; 158:111-17.

9. Psaty BM, Manolio TA, Kuller LH, et al. Incidence of and risk factors for atrial fibrillation in older adults. Circulation 1997;96:2455-61.

10. Khairallah F, Ezzedine R, Ganz LI, et al. Epidemiology and determinants of outcome of admissions for atrial fibrillation in the United States from 1996 to 2001. Am J Cardiol 2004;94:500-4.

11. Ruo B, Capra AM, Jensvold NG, et al. Racial variation in the prevalence of atrial fibrillation among patients with heart failure: the Epidemiology, Practice, Outcomes, and Costs of Heart Failure (EPOCH) study. J Am Coll Cardiol 2004;43:429-35.

12. Marcus GM, Olgin JE, Whooley $M$, et al. Racial differences in atria fibrillation prevalence and left atrial size. Am J Med 2010;123:375. e1-7.

13. Lang RM, Bierig M, Devereux RB, et al. Recommendations for chamber quantification: a report from the American Society of Echocardiography's Guidelines and Standards Committee and the Chamber Quantification Writing Group, developed in conjunction with the European Association of Echocardiography, a branch of the European Society of Cardiology. J Am Soc Echocardiogr 2005;18:1440-63.

14. Borzecki AM, Bridgers DK, Liebschutz JM, et al. Racial differences in the prevalence of atrial fibrillation among males. J Natl Med Assoc 2008;100:237-45.

15. Conway DS, Lip GY. Ethnicity in relation to atrial fibrillation and stroke (the West Birmingham Stroke Project). Am J Cardiol 2003;92:1476-9.

16. Zhou Z, Hu D. An epidemiological study on the prevalence of atrial fibrillation in the Chinese population of mainland China. J Epidemiol 2008;18:209-16.

17. Ohsawa M, Okayama A, Sakata K, et al. Rapid increase in estimated number of persons with atrial fibrillation in Japan: an analysis from national surveys on cardiovascular diseases in 1980 1990 and 2000. J Epidemiol 2005;15:194-6.

18. Yap KB, $\mathrm{Ng} \mathrm{TP}$, Ong HY. Low prevalence of atrial fibrillation in community-dwelling Chinese aged 55years or older in Singapore: a population-based study. J Electrocardiol 2008;41:94-8. 
19. Jeong $\mathrm{JH}$. Prevalence of and risk factors for atrial fibrillation in Korean adults older than 40years. J Korean Med Sci 2005;20:26-30.

20. Sliwa K, Carrington MJ, Klug E, et al. Predisposing factors and incidence of newly diagnosed atrial fibrillation in an urban African community: insights from the Heart of Soweto Study. Heart 2010;96:1878-82.

21. Gbadebo TD, Okafor $H$, Darbar D. Differential impact of race and risk factors on incidence of atrial fibrillation. Am Heart J 2011;162:31-7.

22. Magnani JW, Rienstra M, Lin $\mathrm{H}$, et al. Atrial fibrillation: current knowledge and future directions in epidemiology and genomics. Circulation 2011;124:1982-93.

23. Marcus GM, Alonso A, Peralta CA, et al. European ancestry as a risk factor for atrial fibrillation in African Americans. Circulation 2010;122:2009-15.

24. Manolio TA, Gottdiener JS, Tsang TS, et al. Left atrial dimensions determined by M-mode echocardiography in black and white older ( $>$ or $=65$ years) adults (The Cardiovascular Health Study). Am J Cardiol 2002;90:983-7.
25. McGrady M, Krum H, Carrington MJ, et al. Heart failure, ventricular dysfunction and risk factor prevalence in Australian Aboriginal peoples: the Heart of the Heart Study. Heart 2012;98:1562-7.

26. Vos T, Barker B, Begg S, et al. Burden of disease and injury in Aboriginal and Torres Strait Islander Peoples: the Indigenous health gap. Int J Epidemiol 2009;38:470-7.

27. Hill K, Barker B, Vos T. Excess Indigenous mortality: are Indigenous Australians more severely disadvantaged than other Indigenous populations? Int J Epidemiol 2007;36:580-9.

28. Hertz RP, Unger AN, Cornell JA, et al. Racial disparities in hypertension prevalence, awareness, and management. Arch Intern Med 2005;165:2098-104.

29. Ogden CL, Carroll MD, Curtin LR, et al. Prevalence of overweight and obesity in the United States, 1999-2004. JAMA 2006;295:1549-55.

30. Wong CX, Abed HS, Molaee P, et al. Pericardial fat is associated with atrial fibrillation severity and ablation outcome. J Am Coll Cardiol 2011;57:1745-51. 